DOI 10.32370/IA_2019_01_15

\title{
Theoretical - Methodological Features of Training Ceramic Sculpture of Small Forms
}

\author{
Rudoy Vadim Vladimirovich
}

\author{
Senior Lecturer of the Department of Theory and Methodology of Decorative \\ Arts, graphic arts and graphic faculty of the State institution "South Ukrainian \\ National Pedagogical University named after K. D. Ushinsky"
}

\begin{abstract}
The article defines that in modern times they begin to undergo a rethinking of the basis of art education, which also affected the process of teaching ceramics to the students of the Civil Engineering Faculty. Particular attention is paid to ceramic sculpture of small forms, highlighting the theoretical and methodological foundations of education. It is emphasized that the study of ceramic sculpture of small forms, the technique of its implementation by students of the HGF greatly facilitate the learning of creativity, making the result vividly accessible to perception, which, in turn, arouses their interest in the educational process as a whole. It depends on its purpose every time. Modern small plastic designed to overcome the monotony of the mass typical interior, to give it individuality. Affinity of arts and crafts and sculptures of small forms sometimes leads to a double reading of the same thing. It turns out that the theoretical and methodological foundations of teaching ceramic sculpture of small forms are based on the fact that the educational process is built according to three didactic principles: "Scientific", "Systematic", "Visual". The conclusions provide generalizations that in modern times they begin to undergo a rethinking of the basis of art education, which also affected the process of teaching pottery to the students of the Civil Engineering; ceramic sculpture of small forms has its own theoretical and methodological features; teaching ceramic sculpture of small forms, the technique of its implementation is quite relevant, as it greatly facilitates the task of preparing a teacher and artist, and, in turn, optimizes the learning process; special attention in the learning process must be given to the imaginative, associative characteristics of means of artistic expression in the work created by students.
\end{abstract}

Keywords: sculpture, sculpture of small forms, ceramics, ceramic sculpture of small forms.

Introduction. Small sculptures and ceramic decorative sculptures are of particular interest. This is due to the fact that the category of artistic style ceases to be unshakable, the boundaries between arts, between easel and monumental are revised, artistic conceptuality firmly entered into practice, which implies the emergence of a dialogue with the audience, the measure of reflection of the authors' personal views on classical canons is revised. Naturally, this also affected the process of teaching students of the HGF. The study of small-sized 
ceramic sculpture, the technique of its implementation by students of the HGF greatly facilitate the learning of creativity, making the result vividly accessible to perception, which, in turn, arouses their interest in the educational process as a whole.

The degree of elaboration of the problem. Fundamental ideas about monumental and decorative sculpture, small forms of sculpture contribute to various scientific works, many of which are analytical and conceptual in nature. In the works of M. Ginzburg, I. Lang, G. Motovilova, N. Odnaralova, N. Polyakova, I. Svetlova and others reveal the main ideas about sculpture $[1 ; 3 ; 4 ; 5 ; 6 ; 8]$. The development of students' creative abilities in the arts and crafts class was reviewed by: M. Dadoboeva, R. Ibragimova, V. Koreshkov, I. Marchenko, A. Surin, M. Sukhareva, L. Trubnikova, T.Yu. Von Arb-Knorozok, T. Shpikalova and others. A number of studies (I. Alekseeva, I. Byshek, I. Kozlov, V. Koreshkov, A. Prishchepa, L. Trubnikova, A. Udartseva, A. Khvorostov) emphasized the importance of decorative art, outlines the ways and means of enhancing the educational process, considered the content and methods of teaching various types of decorative art.

Insufficiently lit parts of the problem. Identification of methodological features of teaching small-sized ceramic sculpture as an important component in teaching students in art education.

The purpose of our article is to examine ideas about sculpture and sculpture of small forms. To reveal the theoretical and methodological foundations of teaching ceramic sculpture of small forms and to reveal the main principles for obtaining creative results.

The main content (research methodology). The theoretical and methodological foundations of teaching ceramic sculpture of small forms are based on the fact that the learning process should be built according to three didactic principles: "Scientific", "Systematic", "Visibility". Therefore, it is necessary to pay attention to the process of creating a ceramic sculpture of small forms (from design, creation of an artistic image, to finding a form of expression and embodiment in the material).

The main content (Discussion). Sculpture as an art form has a special meaning for each era. Sculpture (lat. Sculptura, from sculpo-carving, carving) is a type of fine art, whose works have a volumetric shape and are made of solid or plastic materials. In the broad sense of the word, it is the art of creating clay, wax, stone, metal, wood, bone and other materials to depict humans, animals, and other objects of nature in tactile, bodily forms. Sculpture (lat. Sculpture, 
from sculpo - carving, carving), sculpture, plastic - a form of fine art, whose works have three-dimensional form, three-dimensional and tangible. The sculpture is divided into types: easel, monumental, monumental-decorative sculpture, small plastic. The word sculpture, in addition to the very type of art, also means each of his individual works. The sculpture has a specificity, features of the artistic language, the main issues, terminology. The main genres of sculpture are: portrait; historical; mythological; domestic; symbolic; allegorical; animalistic The artistic and expressive means of the sculpture are: building a volumetric form; plastic model building (modeling); silhouette development; development of texture (in some cases also colors). The method for producing the sculpture depends on the material: plastic increasing the volume of the sculpture by adding a soft material (clay, wax); Sculpting cutting off excess parts of solid material (stone and other materials); casting - the product arises due to the infusion into the form of molten metal (bronze, for example). Regarding the material and method of image execution, sculpture, in the broad sense of the word, splits into several industries: modeling or modeling is the art of working with soft material, like wax and clay.

The main requirements for sculpture consist of the following. Sculpture, as a voluminous art, requires the appropriate organization of the surrounding space. Issues of synthesis with architecture is one of the most important in the understanding and perception of monumental and monumental-decorative sculpture. The expressiveness of the sculpture is achieved through the construction of basic plans, light planes, volumes, masses, rhythmic relationships. Of great importance are the clarity and integrity of the silhouette. Textured surface finish and details complement the expressiveness of the plastic solution of the sculptural image.

Ceramic sculpture of small forms as an art form implies the following. Sculpture of small forms - works of small plastic, made from clay, porcelain, earthenware, metal, stone. The art of small-scale sculpture originates in ancient times, in the prehistoric culture of CroMagnon Venus and totem figures. It includes - a huge variety of areas, materials, techniques. Nevertheless, the criteria in the approach to the definition of the concept "sculpture of small forms" are not defined. Legalized only the parameters by which the height and length of the work can be increased to eighty centimeters and one meter. Small plastic is a type of art of 
sculpture, which obeys its laws, carries its features, and among them the main one is the desire for psychologism and generalization. At the same time - the sculpture of small forms closely adjoins the arts and crafts. Small plastic can be replicated industrially, which is typical for samples of applied art and not typical for easel sculpture. It happens that arts and crafts and small forms of sculpture form a kind of symbiosis and relate to each other, like the architecture of a building with a round sculpture adorning it.

Often the sculpture of small forms makes up a single, integral ensemble with objects of decorative and applied art. The sculpture of small forms initially develops in two directions as the art of mass things and as the art of unique, isolated works. It depends on its purpose every time. Modern small plastic designed to overcome the monotony of the mass typical interior, to give it individuality. Affinity of arts and crafts and sculptures of small forms sometimes leads to a double reading of the same thing. According to S.Kh. Rappoport, "the harmonious combination of applied, decorative and artistic components in the creation of things of the objective world is a prerequisite for the design activities of specialists of an artistic profile. In these conditions, in the process of designing artistic expressive-semantic elements of decorative arts, associative capabilities of the products themselves, as well as the principles of their organization as artistic and fun tional facilities is the only approach to designing products that have applied and artistic value is realized one of the leading principles of arts and crafts - a harmonious unity of artistic and expressive, utilitarian and functional structure of the product of logic"[7, $51 \mathrm{c}$.$] .$

The theoretical and methodological foundations of teaching ceramic sculpture of small forms emanate from three didactic principles: "Scientific", "Systematic", and "Visibility":

- "Scientific". Associated with knowledge of terminology. It is possible to identify the main ones: plastic material, layer, spatula, stacks, plastic model masa, slip, accent, model (in sculpture), proportion, table for modeling, stack. From compositional terminology: styling, technology, texture. Sketch, etude.

- "Systematic". Compositional construction is one of the most important artistic means of sculpture. Composition - the ratio, the relative position of the clock. The basis of the sculptural composition is the design, the most obvious expression of which is the frame of the clay model. However, the construction, depending on the material, static in its essence, cannot 
be the carrier of the sculptural artistic image, it is only an element, although the most important, of the general compositional solution of the work of art. According to the sculptor N. Domogatsky, "the physical construction does not coincide with the artistic one. The criterion is our understanding of the design possibilities of this material, which does not always coincide with reality and changes. Thus, the constructive possibilities of stone, especially marble, are usually narrowed; bronze is usually the opposite" [2, p. 111].

- "Visibility": there is a concept about a concept - an idea (without a clear message, this is an empty thing, although it has a beautiful form - a shell); connections do not decorate (this is about how everything is important in the concept. Form makes sense, and you need to experiment with forms and details in order to get interesting effects, but if all along - without taking into account what they mean and how they support each other in general, in the end it is mixed masses of garbage); use one or two creatively verified blows! (focus on one important detail - things, and then bringing it through the rest. If there is no clear focus for the beginning, there is no longer integrity); choosing colors as a goal (not just to capture some colors from the air, but to know what colors will do when to combine them. Choose colors that work, not those that were expected); if it is possible to do something with lower costs, it is necessary to do it (this is a difficult job, but there is a big difference between the "complex" and the "simple complex" - a simple context); the magic of negative space. Create it, don't just fill it! (if the space is simply filled, then as a result the presentation of the accumulation of details. The absence of negative space also overwhelms and confuses); measure with my own eyes: visual quality (the thing that looks like it should look like it should be according to the concept); create an image, and not collect it from dissimilar parts; static equals boring (static compositions say that it is not understood where it was necessary to go); know the history of art, but not repeat it (learn from the works of others, but do your own work); symmetry is an absolute evil.

Conclusions. On the basis of the analyzed material it is possible to make certain generalizations and conclusions. Based on the presented material it is possible to make generalizations:

- in modern times they begin to undergo a rethinking of the basis of art education, which also affected the process of teaching pottery to the students of the Civil Engineering; 
- ceramic sculpture of small forms has its own theoretical and methodological features;

- training in small-scale ceramic sculpture, its implementation technique is quite relevant, since it greatly facilitates the task of preparing a teacher and artist, and, in turn, optimizes the learning process;

- special attention in the learning process must be paid to the figurative, associative characteristics of the means of artistic expression in the work created by students.

Prospects for further research. It is necessary to research new methodological opportunities for students to create small-sized ceramic sculptures, including attention to the concept, creating an artistic image, finding the form of expression and embodiment in the material.

\section{References}

1. Ginzburg M. Functional method and form. Modern architecture. 1926. No. 4. P. 89-92.

2. Domogatskiy N.V. Theoretical works, research. Letters of the artist. Moscow, 1984. 111 p.

3. Lysenko L. From a live theme to a lively form. Creativity. 1982. No. 10. P. 28-30.

4. Malinina T.G. Formula style. Art Deco: origins, regional variations, features of evolution. Moscow: Pinakothek. 2005.

5. Odnoralov N.V. Sculpture and sculptural materials: A Handbook for Art Universities. Moscow, 1982.

6. Polyakova N.I. Sculpture and Space: Study Guide. Moscow: Owls. Artist, 1982.

7. Rappoport S.Kh. Aesthetic creativity and the world of things. Moscow: Knowledge, 1987. $54 \mathrm{p}$.

8. Svetlov I.Ye. On modern sculpture: Study Guide. Moscow: Owls. Artist, 1982. 